\title{
A Collision Tumor with Squamous Cell Carcinoma of Skin Overlying Breast and Invasive Breast Carcinoma
}

\author{
Ozlem Ceren Gunizi ${ }^{1}$ and Hasan Calis ${ }^{2}$ \\ ${ }^{1}$ Department of Pathology, Medical School of Alanya Alaaddin Keykubat University, Turkey \\ ${ }^{2}$ Department of General Surgery, Medical School of Alanya Alaaddin Keykubat University, Turkey
}

\begin{abstract}
Invasive breast cancer is the most common carcinoma in women. Invasive ductal carcinoma, not otherwise specified (NOS), is the largest group of invasive breast cancers. The second most common cancer of skin is squamous cell carcinoma (SCC). Collision tumor is a very rare and unusual tumor. It is defined as the concrescence of two distinct primary neoplasms at one site. Herein, we report a 56-year- female patient who had a collision tumor in the right breast, composed of moderately differentiated squamous cell carcinoma (SCC) and invasive breast carcinoma NOS. In the literature, collision tumors in the breast are very rare and reported in various combinations, but there is only one reported case with SCC and invasive breast cancer, the same as in our case.
\end{abstract}

Key Words: Collision tumor, Squamous cell carcinoma, Invasive breast carcinoma.

How to cite this article: Gunizi OC, Calis H. A Collision Tumor with Squamous Cell Carcinoma of Skin Overlying Breast and Invasive Breast Carcinoma. J Coll Physicians Surg Pak 2021; 31(02):225-227.

\section{INTRODUCTION}

Invasive breast cancer is the most common carcinoma in women. ${ }^{1}$ Invasive ductal carcinoma, not otherwise specified (NOS), comprises the largest group of invasive breast cancers. ${ }^{2}$ The second most common skin cancer of the human body is squamous cell carcinoma (SCC). ${ }^{3}$ Collision tumor is an extremely rare tumor. It is defined as the concrescence of two distinct primary neoplasms at one site. Collision tumors in the breast are very rare and reported in various combinations. ${ }^{4}$ We, herein, report a patient with a collision tumor in the breast. It presented as an invasive breast carcinoma and SCC of the skin overlying the breast. Our case is the second case in the literature.

\section{CASE REPORT}

A 56-year female patient came to our clinic with a mass in the right breast, for the last one year. The symptoms were pain, discharge from the nipple, nipple inversion, and an ulcer in the overlying breast skin. She had no family history of breast cancer. She had not a recent mammogram. Magnetic resonance imaging (MRI) scans revealed a mass in the right breast in the upper outer quadrant measuring about $7 \times 5.5 \mathrm{~cm}$ (Figure 1).

Correspondence to: Dr. Ozlem Ceren Gunizi, Department of Pathology, Medical School of Alanya Alaaddin

Keykubat University, Turkey

E-mail: cerenuzun07@hotmail.com

Received: February 09, 2019; Revised: November 22, 2019;

Accepted: December 09, 2019

DOI: https://doi.org/10.29271/jcpsp.2021.02.225

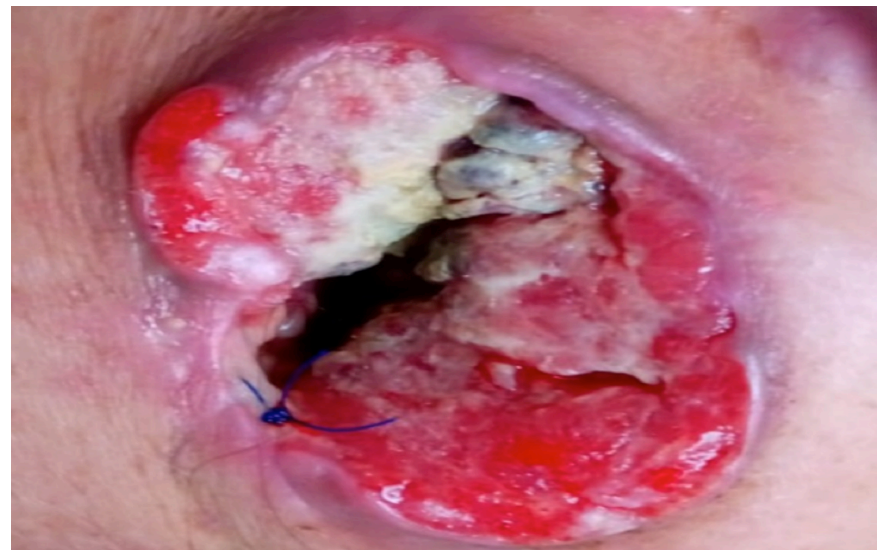

Figure 1: Tumor mass with extensive necrosis and ulceration seen in the right breast after local surgical excisional biopsy.

There was a right axillary lymph node about $1 \mathrm{~cm}$ in size. It was reported as a breast imaging-reporting and data system (BIRADS) category 5. The left breast was normal and reported as a BI-RADS category 1. A local surgical excisional biopsy was performed. The preliminary clinical diagnosis was inflammatory breast carcinoma. At macroscopic examination, there was minimal skin and the tumoral mass was completely ulcerated in superficial biopsy. In the gross examination, the two different resected specimensmeasured, the surficial one $5 \times 4.5 \times 1.5 \mathrm{~cm}$, and the deep one $3.5 \times 1.5 \times 1.5 \mathrm{~cm}$. On cut sections, a firm, white, homogeneous solid mass lesion was noted. The histopathologic examination of mass showed two different tumor types. Microscopic examinations of the masses showed moderately differentiated squamous cell carcinoma (SCC) extending from the skin (Figure 2, 3), and invasive breast carcinoma, NOS (Figure 4). The SCC consisted of tumor cells that infiltrated deep 
into the dermis with pleomorphic nuclei, prominent nucleoli, and abundant eosinophilic cytoplasm. Some of these tumor cell nest to showed keratin pearls. Invasive breast carcinoma cells were arranged in cords, glands, and trabeculae. Some of these cells were like SCC, because the tumor cells had pleomorphic nuclei, prominent nucleoli, and abundant eosinophilic cytoplasm. Ductal carcinoma in situ and microcalcifications were noted. Mitotic activity was extensive and atypical mitoses were present. There were no lymphovascular invasion and perineural invasion. The margins were positive in both biopsy specimens. There was only breast cancer in the second biopsy sample.

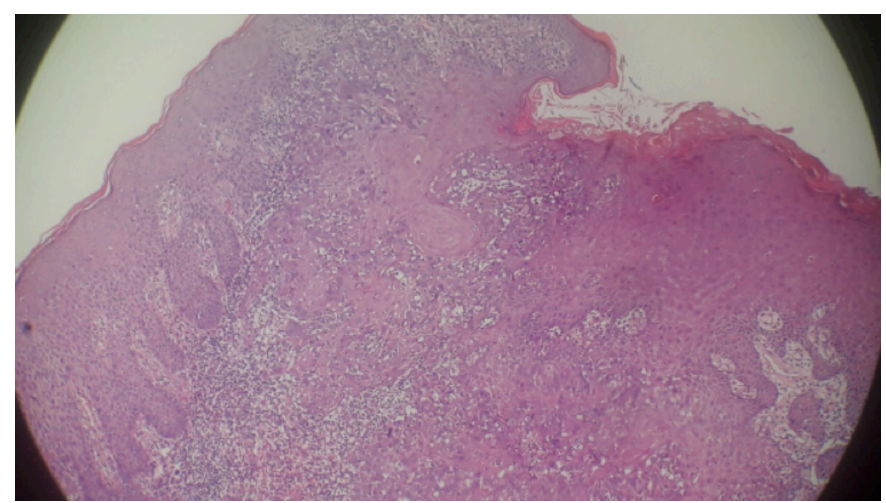

Figure 2: Squamous cell carcinoma extending from breast skin (H\&E

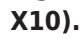

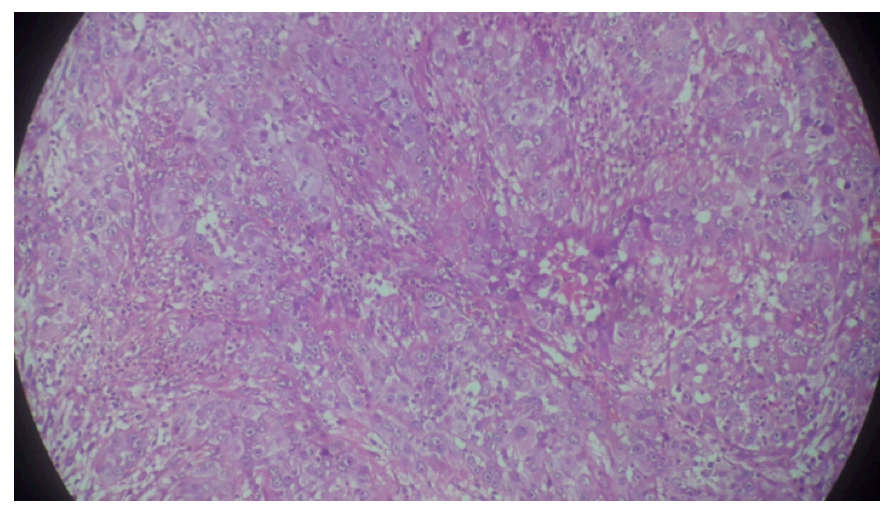

Figure 3: Moderately differentiated squamous cell carcinoma, showing mitotic figures and pleomorphism (H\&E X20).

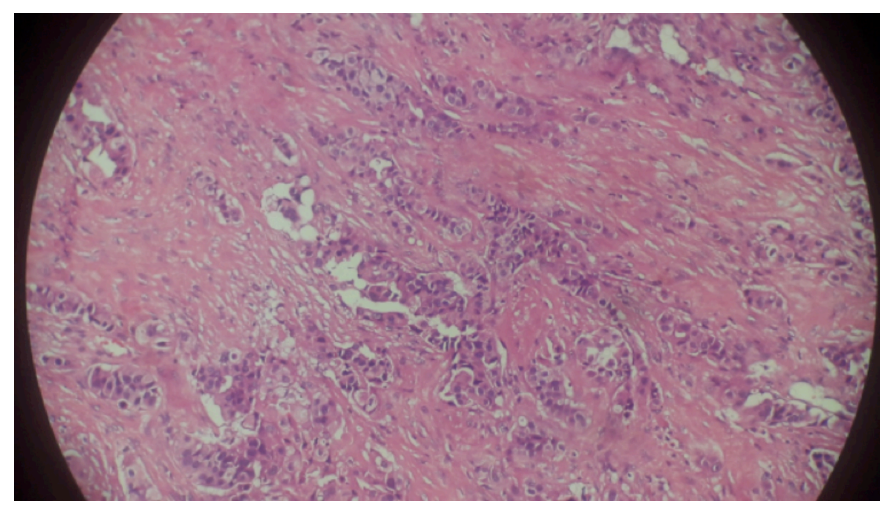

Figure 4: Invasive breastcarcinoma (H\&EX20).

The invasive breast carcinoma was scored using the Bloom-Richardson system as grade 2. The microscopic diameter of breast carcinoma was $1.8 \mathrm{~cm}$; and of SCC, $2 \mathrm{~cm}$. The immunohistochemical analyses showed that the SCC tumor cells were positive for HMWK, CK 14, and P 63. The invasive breast carcinoma was positive for mammoglobin, GCDFP-15, ECadherin, and MUC-1. These cells were negative for $\mathrm{BCl}-2$, CK5/6, and P 63. Prognostic factors for breast carcinoma ER 80\% +2 , and PR $90 \%+3$ were positive, and CerbB2 (HER2) was negative. The Ki-67 proliferation index was 30\%. All three receptors (ER, PR, and HER2) were negative in the SCC. After the postoperative follow-up, the patient was referred to another hospital for chemotherapy treatment.

\section{DISCUSSION}

Invasive breast cancer is the most common carcinoma in women. ${ }^{1}$ As with most epithelial tumors, the incidence of breast cancer increases with age. ${ }^{2}$ Invasive breast carcinoma, not otherwise specified (NOS), known as ductal carcinoma, NOS, is the largest group of invasive breast cancers. ${ }^{2}$

The second most common skin cancer of the human body is squamous cell carcinoma (SCC). It frequently occurs on sun-exposed areas of the body. ${ }^{3}$ Synchronous malignancies are uncommon in the literature. A review of the literature with 8,428 autopsy results showed that $68(0.8 \%)$ patients had multiple primary tumors. There were synchronous cancers in only 15 patients. In that series, breast cancer had the second highest incidence rate (5.5\%). The rate of breast cancer being associated with another primary malignancy was very low (2\%). None of them were synchronous with other tumors. ${ }^{4}$

Collision tumors have been reported in the breast in various combinations. There is only one case with the same combination as in our case. ${ }^{5}$ Some of the other reports are of inflammatory carcinoma and a malignant phyllodes tumor, invasive ductal carcinoma in association with mucosa-associated lymphoid tissue (MALT) lymphoma, invasive ductal breast cancer with plasma cell myeloma, and metastatic squamous cell carcinoma with invasive lobularcarcinoma. ${ }^{6-8}$

SCC of the breast should be differentiated between primary skin keratinized squamous carcinoma and squamous metaplastic cancer. ${ }^{8}$ In our case, the skin was involved by tumor, and the breast skin epithelium was associated with SCC. Breast skin is very rare location for SCCs. In the literature, there is a reported case of epidermoid carcinoma of the nipple after radiotherapy. ${ }^{9}$ Breast skin SCC is very rare in case reports, but prognosis is excellent when compared with metaplastic SCC. ${ }^{10}$ Accordingly, patient history, physical examination, and correct diagnosis are very important for choosing the correct treatment.

Invasive breast carcinoma is a tumor, originating from the terminal ductal-lobular unit. It is graded, based on the amount of tubule formation, nuclear atypia, and mitosis per 10 high-power fields (HPF). It usually appears in axillary lymph nodes, and other organs such as lungs and bone. The behaviour of the tumors and treatment depends on the higher grade of either of the tumors, mitotic activity, resected margin status, skin involvement, and metastasis. ${ }^{2}$ 
Subtype and pathologic stage of aggressive tumors of the breast influence the clinical prognosis of collision tumor. ${ }^{6}$ In our case, prognosis was dependent on the invasive breast carcinoma. Therefore, chemotherapy treatment was chosen for our patient after radical mastectomy. There is no standard treatmentfor collision tumors because of their rarity.

We reported here a very rare case of collision tumor comprising of invasive breast carcinoma, NOS and SCC of the skin overlying the breast, only the second case in the literature. Given the lack of standard treatment for these extremely rare cases, treatment is based on SCC and invasive breast carcinoma treatment. There is a need of multimodal approach in these cases, which includes extensive surgery with axillary dissection. Surgical treatment should be performed with adjuvant radiation therapy and chemotherapy.

Patients Consent: Written informed consent was obtained from the patient for the publication of this case report and accompanying images.

\section{CONFLICT OF INTEREST:}

Authors have no conflict of interest to declare.

\section{AUTHORS' CONTRIBUTION:}

OCG: Drafting the manuscript, revising it.

$\mathrm{HC}$ : Collecting case information.

\section{REFERENCES}

1. Bray F, Ferlay J, Soerjomataram I, Siegel RL,Torre LA, Jemal A. Global cancer statistics 2018: Estimates of incidence and mortality worldwide for 36 cancers in 185 countries. CA Cancer J Clin 2018; 68(6):394-424. doi: 10.3322/ caac. 21492 .

2. Lakhani SR, Ellis IO, Schnitt SJ, Tan PH, van de Vijver MJ. WHO classification of tumours of the breast. 4th ed. Lyon:
IARC; 2012. pp. 12-34 and 143-7. ISBN-13 (Print Book) 978-92-832-2433-4

3. Rahimi S, Squamous cell carcinoma of skin: A brief review. Clin Ter 2013; 164(2):143-7. doi: 10.7417/CT.2013.1534.

4. Lee TK, Myers RT, Scharyj M. Multiple primary malignant tumors (MPMT): Study of 68 autopsy cases (1963-1980). J Am Geriatr Soc 1982; 30(12)pp.744-53 doi: 10.1111/ j.1532-5415.1982.tb03364.x.

5. Geetha RL, Kalyani R, Srinivas MV, Shakthidasan C. A rare collision tumour of Infiltrating ductal carcinoma and squamous cell carcinoma of skin overlying breast: A case report. J Clin Diagn Res 2015; 9(1):XD06-XD08. doi: 10.7860/JCDR/2015/10437.5464.

6. Shin YD, Lee SK, Kim KS, Park MJ, Kim JH, Yim HS, et al. Collision tumor with inflammatory breast carcinoma and malignant phyllodes tumor: A case report and literature review. World J Surg Oncol 2014; 12:5. doi: 10.1186/ 1477-7819-12-5.

7. Quilon JM, Gaskin TA, Ludwig AS, Alley C. Collision tumor: Invasive ductal carcinoma in association with mucosaassociated lymphoid tissue (MALT) lymphoma in the same breast. Southern Medical J 2006; 99(2):p164-7. doi: 10.1097/01.smj.0000198640.58397.c5.

8. Moosavi L, Farjami S, Shane L, Hosseini A, Choi C. A collision tumor with features of breast cancer and plasma cell myeloma as primary tumors. J Med Cases 2018; 9(9):309-12. doi: http://doi.org/10.14740/jmc3117w.

9. Khan MI, Haque AU, Younar M, Zafar A, Shah H. Metaplastic squamous cell carcinoma in association with invasive lobular breast carcinoma with metastasis to axillary lymph nodes. J Ayub Med Coll Abbottabad 2011; 23(4):135-7.

10. Loveland-Jones CE, Wang F, Bankhead RR, Huang Y, Reilly $\mathrm{KJ}$. Squamous cell carcinoma of the nipple following radiation therapy for ductal carcinoma in situ: A case report. J Med Case Reports 2010; 4:186. doi: 10.1186/ 1752-1947-4-186. 